UDC 93

Submitted: 30.11 .2015

LBC 63.3(2)51

Accepted: 25.03.2016

\title{
FROM THE HISTORY OF LACE CRAFT IN THE SOUTH BLACK EARTH RUSSIA (2ND HALF OF THE 19TH CENTURY - BEGINNING OF THE 20TH CENTURY)
}

\author{
Viktoriya A. Grigorova \\ Voronezh State Technical University, Voronezh, Russian Federation
}

\begin{abstract}
The author studies the specifics of lace in the territory of the South Black Earth Russia in the 19th early 20th centuries. The author has analyzed the history of lace crafts in the Yelets and Mtsensk districts of the Orlovsk province, and in the Zadonsk district of the Voronezh province. Based on archive materials the article determines such features of lace crafts development as the uniqueness of lace; the dependence of the growth of the influence of buyers on the pace of industry development; presence of the qualitative indicators of the manufacturing process inversely proportional to the quantitative; expanding the range of manufactured lace; the expansion of the sales area of lace; activation of the attention of individuals and public institutions to revive the specificity and individuality of local products lace. It was concluded that the impact of identified features on the pace of development of the lace industry in the South Black Earth Russia and on the development of Russian business in general.

Analyzing the history of lace crafts, the author describes the conditions of industrial activity lace, which showed the formation of the capitalist forms of lace makers' work. The features of the capitalist forms of labour which characterized crafts activity are pointed out. The peculiarities of lace sales organization in local and distant markets are studied. In addition to interprovince and interdistrict markets the author investigates the material on exporting goods abroad. The main reasons for the expansion of sales geography determine the change in product mix.

The author raises the issue related to the history of the preservation of unique lace made following the traditions of Russian folk art of their ancestors. The problem consisted in the fact that the buyers were not interested in the originality and identity of the goods. As a result, this led to the reduction of the original performance by increasing the amount of work on the standard models.
\end{abstract}

Key words: lace craft, lace makers, Eletsk district, Mtsensk district, Zadonsk district, South Black Earth Russia.

УДК 93

ББК 63.3(2)51

Дата поступления статьи: 30.11.2015

Дата принятия статьи: 25.03.2016

\section{ИЗ ИСТОРИИ РАЗВИТИЯ КРУЖЕВНОГО ПРОМЫСЛА ЧЕРНОЗЕМНОГО ЮГА РОССИИ (2-я ПОЛОВИНА ХІХ - НАЧАЛО ХХ в.)}

\author{
Виктория Александровна Григорова \\ Воронежский государственный технический университет, г. Воронеж, Российская Федерация
}

\footnotetext{
6 Аннотация. В статье выявляются специфические особенности развития кружевного промысла на терри을 тории Черноземного юга России в XIX - начале XX в. в Елецком, Мценском уездах Орловской губернии и в Задонском уезде Воронежской губернии. На основе архивного материала определяются такие особенности их развития, как уникальность кружев; зависимость роста влияния скупщиков от темпов развития промысла; нали๘ чие обратно пропорциональной зависимости количественных и качественных показателей производственного процесса; расширение ассортимента изготавливаемого кружева; расширение района сбыта кружев; активизация внимания частных лиц и общественных учреждений к возрождению характерности и индивидуальности изделий местных кружевниц. Был сделан вывод о влиянии обозначенных особенностей на темпы развития кружевного промысла Черноземного юга России и на развитие предпринимательства России в целом.
} 


\section{РЕГИОНОВЕДЕНИЕ}

Анализируя историю развития кружевных промыслов, автор охарактеризовал условия производственной деятельности кружевниц. Были обозначены черты, которые свидетельствовали о формировании капиталистических форм труда в промысловой деятельности. Отдельно рассмотрены особенности организации сбыта произведенных кружев на местных и удаленных рынках. Помимо межволостного, внутригубернского, внутриуездного рынков, был исследован материал об экспорте товаров за границу. Основными причинами расширения географии сбыта определялись изменения в ассортименте продукции.

В статье автор поднимает вопрос, связанный с историей сохранения уникальности изготовленных кружев, с обращением к традициям русского народного творчества предков. Проблема заключалась в том, что оригинальность и самобытность товара мало интересовали скупщиков. В результате это обусловило снижение оригинальности исполнения при увеличении объемов работы по стандартным образцам.

Ключевые слова: кружевной промысел, кружевницы, кружевоплетение, Елецкий уезд, Мценский уезд, Задонский уезд, Черноземный юг России.

В дореформенный период одним из самых распространенных видов кустарных промыслов России было кружевоплетение. В 17 губерниях насчитывалось около 100 тыс. мастериц, из которых практически половина регистрировались в Елецком уезде Орловской губернии. Учет традиций развития кружевоплетения Черноземного юга России пореформенного периода представляется важным для совершенствования руководства крупными современными предприятиями, такими как ЗАО «Елецкие кружева», в цехах которого и сегодня выпускаются строчевышитые изделия, а также при разработке направлений государственной политики в отношении мелких товаропроизводителей, работающих у себя на дому и создающих уникальные авторские работы, что обогатит творческую практику современного искусства.

Актуальность исследования истории кружевного промысла усиливается пробелами современной историографии, в которой до сих пор отсутствуют комплексные работы, освещающие процесс зарождения и развития кружевоплетения в регионе.

Основным пунктом развития был г. Елец и близлежащие села. Здесь на рубеже XIXXX вв. прослеживалась тенденция, связанная с ростом числа мастеров-кружевниц. Так, в 1886 г. в Елецком уезде было зарегистрировано 11604 человек, занятых в данном промысле. А в 1910 г. уже насчитывалось 28200 кружевниц. Подобная ситуация наблюдалась и в Воронежской губернии, где в 1880 г. насчитывалось всего 27 кружевниц, а в 1912 г. уже около 1000 женщин среди местного населения занимались кружевоплетением [7, с. 142].

В соответствии с документами Воронежской губернской земской управы популярность данного промысла среди местных жителей объяснялась:

1. Независимостью от географических и экономических условий местности.

2. Простотой и дешевизной приспособлений.

3. Отсутствием требований к помещению.

4. Незначительностью затрат на материал (5-25 \% от стоимости готового изделия).

5. Наличием различных возможностей: работы на дому, сбыта изделий на месте производства, привлечения к труду детей и подростков [5, с. 5].

Кроме того, развитию кружевоплетения способствовало появление более широкого рынка в связи с постройкой железных дорог и развитие модных тенденций в 70-е гг. ХІХ в., связанных с необходимостью отделки кружевом элементов верхней женской одежды [4, с. 56].

В кружевоплетении были заняты представители различных социальных категорий. До 50-х гг. ХIX в. плетением кружев занимались исключительно в купеческих и дворянских семьях. На данном этапе промысел развивался в виде досуговой деятельности по производству изделий, служащих украшением одежды. Впоследствии, в частности в пореформенный период, кружевоплетением стали заниматься для продажи на рынках и на заказ. С этого времени промысел получил активное распространение и в крестьянской среде. Девушки под руководством матери или близких родственников с раннего детства постигали основы данного производства. Они обучались плетению из шелка, бумажной пряжи, шерсти и льняных ниток.

На территории Черноземного юга России кружевной промысел был известен в Елецком и Мценском уездах Орловской губернии 
и в Задонском уезде (в волостях: Ивовской, Докторовской, Нижнестуденецкой) Воронежской губернии [5, с. 10]. Он развивался в условиях конкуренции на всероссийском рынке сбыта с известным в России вологодским кружевом. Распространению кружевоплетения в регионе способствовали локальные особенности, выявленные на основе анализа документов «Воронежской губернской земской управы» и других фондов Государственного архива Воронежской области.

1) Уникальность кружев, которые отличались высоким качеством исполнения, богатством орнаментальных мотивов, тонкостью работы. При этом важно заметить, что разнообразие орнаментальных мотивов складывалось под влиянием ровного степного Елецкого пейзажа. Об этом свидетельствуют местные старые названия орнаментов кружев, такие как «жучки», «мушки», «травчатый рубчик» и т. д. [8, с. 13].

Кружево, изготовленное мастерами Воронежской губернии, отличалось русской этнической традицией. Однако постепенно старинные способы работы и рисунка забывались. Их начали заменять полуфабричные образцы, которые присылались из Московского кустарного склада.

В начале 60-х гг. XIX в. кружево, изготовленное местными мастерицами Черноземного юга России, впервые появилось на рынке наряду с другими товарами кустарного производства [5, с. 12]. В 70-80-е гг. XIX в. оно представлялось в качестве выставочных экспонатов на ярмарках и выставках [6, с. 17]. Например, в 1885 г. на Нижегородской ярмарке кустарных промыслов и сельского хозяйства было выставлено 628 экспонатов, среди которых представлялось кружево. На Всероссийской сельскохозяйственной выставке в Харькове учреждалось специальное отделение смешанных и более сложных производств в составе VII отдела выставки - «Кустарные промыслы». В соответствии с программой выставки в данном отделении регистрировались экспонаты, связанные с производством детских игрушек, кружев и фосфорно-спичечного промысла [6, с. 33].

2) Зависимость роста влияния скупщиков от темпов развития промысла. Подтверждением являются документы Bopo- нежской губернской земской Управы - в частности «Дело об организации кустарных промыслов». Анализ данных документов позволил заключить, что скупщики были заинтересованы в расширении ассортимента. Учитывая различный вкус покупателей, они привозили кружевницам новые узоры, тем самым обогащая рынок новыми видами кружев, которые постепенно вытесняли старые узоры, и подавляли инициативу талантливых кружевниц. Так, например, кружевницы Задонского уезда Воронежской губернии работали из материала и по образцам, которые предоставляли скупщики. Материал состоял из сколок рисунков на бумагах с проколотыми местами, по которым устанавливались булавки. Их стоимость была достаточно высокой (2-3 рубля для дамского воротника), поэтому только более зажиточные кружевницы могли себе позволить приобретать их в Ельце самостоятельно, без помощи скупщиков.

Негативное влияние скупщиков и торговых посредников прослеживалось и в технике кружевного дела. Занижая закупочные цены, они подталкивали мастеров кружевного дела компенсировать потери в цене за счет скорости исполнения заказа, сокращая рисунок и ухудшая качество работы в целом [5, c. 10-14].

Важно отметить, что взаимоотношения между производителем, скупщиком, купцом никогда не были благополучными. Каждый из них использовал разные уловки, чтобы одним - дороже продать, другим - дешевле купить.

Подтверждением является ситуация, которая складывалась в кружевном промысле в Задонском уезде. Здесь кружевницы получали материал у скупщиц-торговок, которые закупали его в Ельце. За изготовление кружев они платили разными товарами: ситцем, платком и т. д. Но, принимая товар, скупщицы использовали разные уловки, чтобы оценить изготовленное кружево как можно дешевле. Если кружевницы протестовали, то им угрожали, что не будут больше давать заказов. А так как работать на свои деньги без определенного места сбыта и без оборотных средств невозможно, кружевницы покорялись $[5$, c. 10$]$.

3) Негативное влияние скупщиков на темпы развития и технику производ- 
ственного процесса. Для скупщиков индивидуальные особенности местного производства не имели значения. Для них важнее было разнообразие кружев, так как в разных городах они сталкивались с самыми различными покупателями, вкусы которых нужно было удовлетворять. Поэтому качественные, тонкие, тщательно отделанные кружева, которые ценились очень дорого, не интересовали скупщиков. Следовательно, при увеличении количественных показателей сильно снижались показатели качественные.

Данную особенность можно проследить, опираясь на осведомительные материалы «Программы занятий III Всероссийского съезда деятелей по кустарной промышленности 1913 года». В соответствии с докладом Елецкой Уездной Земской Управы Постоянному Бюро Съездов, скупщики Ельца оказывали негативное влияние на развитие кружевного промысла. Они не выделяли из общей массы хорошую, качественную работу, выполненную по образцу. Предлагали низкие закупочные цены. При этом сами кружевницы отличались общей и графической неграмотностью, что вполне устраивало скупщиков. В результате представители Елецкой Уездной Земской Управы причиной снижения качественных показателей считали именно увеличение количественных показателей путем увеличения заказов со стороны скупщиков [9, с. 32-33].

4) Расширение ассортимента изготавливаемого кружева. Изначально в производстве существовало два вида кружев аршинное и штучное. Аршинное отличалось множеством узоров, но в применении было ограничено. Им обшивались края одежды, полотенец, делались различные вставки. Штучное кружево было представлено цельными вещами, такими как косынки, чепчики, шарфы, платья и т. д.

Большой популярностью пользовались «мотивы» - кружевные фигурки (квадраты, треугольники, веточки и т. д.), которые целиком вшивались в белье или платье. Кружевницами производились покрывала на постели и подушки, скатерти, салфетки, дорожки, воротники и блузки. В Елецком уезде развивалось производство особого вида кружев - черных шарфов и косынок из мягкой шелковистой бумаги. В целом, можно заклю- чить, что местные кружевницы выработали особый тип елецкого кружева, отличительной особенностью которого являлся легкий стиль, тонкие, изящные, но достаточно однообразные мотивы.

5) Расширение района сбыта кружев. Он был очень обширным. Кружево поставляли во всю Европейскую Россию, на Кавказ, в Закавказье и в Азиатскую Россию, Финляндию. Так, только в 1860 г. из Ельца по России и в Закавказье было вывезено кружева на 75 тыс. рублей [2, с. 35]. Кружева, изготовленные по старинным рисункам, окрашенные растительными красками, попадали даже в Англию и Америку, где ценились очень высоко.

Первоначально кружево появлялось на местных рынках: межволостном, внутриуездном, внутригубернском. Но по мере увеличения ассортимента география сбыта расширялась, постепенно переходили к экспорту товара за границу. Известны документы, в соответствии с которыми в Воронежскую Губернскую Земскую Управу поступали предложения от товарищества «Хозяин» в Орле по поводу реализации изделий кустарного производства за границу. Также в 1908 г. собственники магазина в Москве предложили оказывать содействие в продаже кружев, изготовленных в Задонском уезде, как крупным продавцам, так и за границу [5, с. 15].

6) Стремление частных лиц и общественных учреждений возродить характерность и индивидуальность изделий местных кружевниц. В Кустарную комиссию по поддержке кружевного промысла поступало много предложений от местных земств. Например, в 1907-1908 гг. на очередном заседании съезда Кустарной промышленности решался вопрос о мерах улучшения развития данного промысла, которые были направлены на организацию техники производства и постановку работы в каждой отдельной семье.

Члены Кустарной комиссии во главе с председателем - В.И. Жуковым (потомственный дворянин Воронежа) в качестве основной меры по активизации развития кружевоплетения на территории Черноземного юга России признавали необходимость открытия школ кружевниц в Задонском уезде Воронежской губернии. Эта школа должна была бы зани- 
маться вопросами продажи сырого материала и сбыта готовых изделий [5, с. 14].

Таким образом, как показывают данные Воронежской Губернской Земской Управы, все перечисленные локальные особенности Черноземного юга России способствовали высоким темпам развития кружевного промысла в регионе во второй половине XIX - начале $\mathrm{XX}$ века. Только в Елецком уезде производимое кружево составляло пятую часть от всего кружевного производства в России. При этом кружевницы накапливали капиталы, вкладывая их в свое дело, что оказало влияние и на развитие предпринимательства России в целом. Расширяя собственное производство, мелкие товаропроизводители подготавливали базу для становления крупного промышленного производства и обусловливали подготовку квалифицированных кадров по обслуживанию производственного процесса возникающих предприятий.

\section{СПИСОК ЛИТЕРАТУРЫ}

1. Водарский, Я. Е. Сельские кустарные промыслы Европейской России на рубеже XIX-XX вв. / Я. Е. Водарский, Э. Г. Истомина. - М. : ИРИ РАН, 2004. $-514 \mathrm{c}$.

2. Ершов, С. П. Елецкие кружева и кружевницы (историко-экономический очерк) / С. П. Ершов. - Елец : ЕГУ им. И. А. Бунина, 2007. - 129 с.

3. Кустарная промышленность России. Женские промыслы в очерках С. А. Давыдовой, Е. Н. Половцевой, К. И. Беренс и Е. О. Свидерской. СПб. : Типо-литография «Якорь», 1913. - 440 с.

4. Мухина, Н. Е. Юго-Восточная магистраль «металла и хлеба»: прошлое и настоящее (к 145-летию создания ЮВЖД) / Н.Е. Мухина // Вестник Воронежского государственного технического университета. - 2011.- Т. 7, № 12-3. - С. 56-59.

5. Об организации кустарных промыслов // Государственный архив Воронежской области (ГАВО). - Ф. И- 20. - Оп. 1. - Д. 4561.

6. Об устройстве в городах и торговых селениях сельскохозяйственных выставок кустарных производств // ГАВО. - Ф. И-20. - Оп. 1. - Д. 722.

7. Перепелицын, А. В. Крестьянское хозяйство центрально-черноземных губерний России в пореформенный период / А. В. Перепелицын, В. Н. Фурсов. - Воронеж : ВГПУ, 2005. - 204 с.

8. Твердова-Свавицкая, 3. М. Очерк кустарных промыслов Елецкого уезда / 3. М. ТвердоваСвавицкая. - М. : Издание оценочно-статистичес- кого отделения Орловской губернской земской управы, 1916. - $128 \mathrm{c}$.

9. Труды III Всероссийского Съезда деятелей по кустарной промышленности в Санкт-Петербурге 1913 г. Вып. 1. Отд. I, II. - СПб. : Типо-литография «Энергия», 1913. - 397 с.

\section{REFERENCES}

1. VodarskiyYa.E., Istomina E.G. Selskie kustarnye promysly Evropeyskoy Rossii na rubezhe XI-XXvv. [Rural Crafts of European Russia at the Turn of 19th20th Centuries]. Moscow, IRI RAN Publ., 2004. 514 p.

2. Ershov S.P. Eletskie kruzheva i kruzhevnitsy (istoriko-ekonomicheskiy ocherk) [Elets Lace (Historical and Economic Essay)]. Elets, EGU im. I.A. Bunina, 2007. 129 p.

3. Davydova S.A., Polovtseva E.N., Berens K.I., Sviderskaya E.O. Kustarnaya promyshlennost Rossii: zhenskie promysly: ocherki [Artisanal Industry of Russia: Feminine Crafts. Essays]. Saint Petersburg, Yakor Publ., 1913. 440 p.

4. Mukhina N.E. Yugo-Vostochnaya magistral "metalla i khleba": proshloe i nastoyashchee ( $k$ 145-letiyu sozdaniya YuVZhD) [Southeastern Railway of "Metal and Grain": Past and Present (to the 145 Anniversary of the SERW)]. Vestnik Voronezhskogo gosudarstvennogo tekhnicheskogo universiteta, 2011, vol. 7, no. 12-3, pp. 56-59.

5. Ob organizatsii kustarnykh promyslov [On the Organization of Crafts]. Gosudarstvennyy arkhiv Voronezhskoy oblasti [State Archive of the Voronezh Region], F. I- 20, Op. 1, D. 4561.

6. Ob ustroystve $\mathrm{v}$ gorodakh i torgovykh seleniyakh selskokhozyaystvennykh vystavok kustarnykh proizvodstv [On Holding Agricultural Exhibitions of Handicraft in Towns and Trade Villages], Gosudarstvennyy arkhiv Voronezhskoy oblasti [State Archive of the Voronezh Region], F. I-20, Op. 1, D. 722.

7. Perepelitsyn A.V., Fursov V.N. Krestyanskoe khozyaystvo tsentralno-chernozemnykh guberniy Rossii v poreformennyy period [Farm Household of Central Black Earth Provinces of Russia in the PostReform Period]. Voronezh, VGPU Publ., 2005. 204 p.

8. Tverdova-Svavitskaya Z.M. Ocherk kustarnykh promyslov Eletskogo uezda [Essay of Crafts in the Eletsky County]. Moscow, Otsenochnostatisticheskoe otdelenie Orlovskoy gubernskoy zemskoy upravy, 1916. $128 \mathrm{p}$.

9. Trudy III Vserossiyskogo Syezda deyateley po kustarnoy promyshlennosti $v$ Sankt-Peterburge 1913 g. Vypusk 1. Otdely I, II [Proceedings of the 3rd All-Russian Congress of Leaders of the Handicraft Industry in Saint Petersburg in 1913. Iss. 1. Sections I, II]. Saint Petersburg, Energiya Publ., 1913. 397 p. 


\section{Information About the Author}

Viktoriya A. Grigorova, Candidate of Sciences (History), Associate Professor, Department of History and Political Science, Voronezh State Technical University, Prosp. Moskovskiy, 14, 394026 Voronezh, Russian Federation, vagrigorova@rambler.ru.

\section{Информация об авторе}

Виктория Александровна Григорова, кандидат исторических наук, доцент кафедры истории и политологии Воронежского государственного технического университета, Московский просп., 14, 394026 г. Воронеж, Российская Федерация, vagrigorova@rambler.ru. 